\title{
Novel Biomarkers Aim at Detecting Metastatic Sentinel Lymph Nodes in Breast Cancer
}

\author{
Behnaz Bakaeean ${ }^{1,2}$, Mehran Gholamin ${ }^{3 *}$, Seyed Abbas \\ Tabatabaee Yazdi ${ }^{4}$ and Mohammad Naser Forghani ${ }^{5}$
}

\author{
${ }^{1}$ Department of Biology, Marvdasht Branch, Islamic Azad University, Marvdasht, Iran; \\ ${ }^{2}$ Department of Biology, Science and Research Branch, Islamic Azad University, Marvdasht, Iran; ${ }^{3}$ Department \\ of Laboratory Sciences, School of Paramedical Sciences, Mashhad University of Medical Sciences, Mashhad, Iran; \\ ${ }^{4}$ Department of Pathology, Mashhad University of Medical Sciences, Mashhad, Iran; ${ }^{5}$ Surgical Oncology \\ Research Center, Mashhad University of Medical Sciences, Mashhad, Iran
}

Received 11 May 2019; accepted 8 July 2019; published online 26 January 2020

\begin{abstract}
Background: Intra-operative molecular diagnostic assays are currently used for the detection of lymph node metastases. The objective of this study was to find new biomarkers to improve diagnostic accuracy in the detection of metastatic axillary lymph nodes in breast cancer patients. Methods: We applied an absolute quantitative real-time RT-PCR to quantitate the expression of CK19, KLK11, and CLEC3A mRNAs in 79 FFPE SLNs from 35 breast cancer patients. The CK19 was confirmed as a standard biomarker, and the level of expression of selected new markers, KLK11 and CLEC3A, was evaluated in pathologically negative and positive SLNs by using absolute quantitative real-time PCR. Results: The overall concordance of the CK19 gene with pathological results was $92.4 \%$ (less than 250 copies) in negative SLNs and $85 \%$ in positive SLNs (more than 250 copies). The sensitivity and specificity of CK19, which were detected by real-time PCR, was $85 \%$ and $46 \%$, respectively. Our results revealed that lower CLEC3A was associated with more lymph node involvement. We could set a cut-off point for CLEC3A with the sensitivity of $78 \%$ and specificity of $60 \%$. Also, the mean $K L K 11$ had a statistically significant reverse correlation with tumor grade $(p=0.017)$. Higher CK19 levels were related to more tumor invasion $(p<$ 0.0001). Conclusion: Regarding the findings, CLEC3A along with CK19 can be used as a promising marker with high sensitivity and specificity for the detection of metastatic SLN. DOI: 10.29252/ibj.24.3.183
\end{abstract}

Keywords: CLEC3A, Kallikreins, Sentinel lymph node

Corresponding Author: Mehran Gholamin

Department of Laboratory Sciences, School of Paramedical Sciences, Mashhad University of Medical Sciences, and Mashhad, Iran;

Tel. \& Fax: (0513) 8846710; E-mail: gholaminm@mums.ac.ir

\section{INTRODUCTION}

$\mathrm{B}$ reast cancer is the common cause of death amongst women and the leading cause of morbidity and mortality worldwide ${ }^{11]}$. Axillary lymph nodes status has a vital role in determining the survival status of patients and prognosis of the disease, helping clinicians to decide the most appropriate surgical procedure and subsequent treatment options ${ }^{[2]}$. A SLN is the first lymph node or groups of nodes to which cancer cells are probably spread from a primary tumor. SLN biopsy is a surgical procedure to diagnose if cancer has spread to the lymphatic system ${ }^{[3]}$. Frozen section or touch imprint is a routine method used during surgery for the analysis of the SLN and allow rapid $\mathrm{H} \& \mathrm{E}$ staining ${ }^{[4]}$. Understandably, the accuracy

List of Abbreviations:

AUC, area under the curve; CK19, cytokeratin 19; CLEC3A, C-type lectin domain family 3 member A; Ct, threshold cycle; FFPE, formalin-fixed paraffin-embedded; H\&E, hematoxylin and eosin; IDC, invasive ductal cancer; KLK11, kallikrein11; MUC1, mucin 1; ROC, receiver operating characteristic; RT-PCR, reverse transcription-PCR; SLN, sentinel lymph node 
and dependability of these methods rely heavily on the expertise of a cytopathologist and may vary based on institution or clinical setting ${ }^{[5]}$. Due to mistakes in common pathological techniques and the false-negative results, a sensitive and simple method for accurately determining the staging of breast cancer is needed ${ }^{[7]}$. RT-PCR is a highly sensitive diagnostic tool able to detect molecular biomarkers such as MUC1, CK19, and carcino-embryonic antigen in lymph node metastases in patients with invasive breast cancer $^{[8-10]}$.

CK19 is one of the most popular molecular biomarkers and an epithelial cell marker that is not expressed in normal axillary lymph node tissue ${ }^{[11]}$. The amount of CK19 mRNA expression is related to the level of metastatic foci ${ }^{[12]}$. CK19 mRNA, the most proper marker, exists in high levels in metastatic (not non-metastatic) lymph nodes. Accordingly, it has a high sensitivity potency and ability to identify metastatic from non-metastatic lymph nodes ${ }^{[11]}$. Based on previous research, the cut-off value is determined by the number of copies of CK19 mRNA as a criterion to distinguish negative nodes (less than 250 CK19 mRNA copies) from micrometastases (250-5000 CK19 mRNA copies or $>0.2-2 \mathrm{~mm}$ in diameter) and macrometastases (more than 5000 CK19 mRNA copies $)^{[13]}$.

According to the recent next generation sequencing studies, CLEC $3 A$ and $K L K 11$, are overexpressed in metastatic lymph nodes ${ }^{[14]}$. CLEC $3 A$ is a protein related to the great family of C-type lectins and can be seen in normal human breast tissue, but not in any other normal human tissue ${ }^{[15-17]}$. This protein is a heparin-binding, cell adhesion modulator that have capability to alter tumor cell invasion and metastasis by modulating tumor cell adhesion and the plasminogen/plasminogen-activator system $^{[18]}$. Kallikreins are a subgroup of serine proteases, enzymes capable of cleaving peptide bonds in proteins, and a family of 15 genes on chromosome $19^{[19]}$. Studies have revealed the expression of KLK11 in ovarian, prostate, breast, lung, pancreas, and colon cancer tissue ${ }^{[20-22]}$. It has also been indicated that $K L K 11$ expression is regulated by steroid hormones such as estrogen ${ }^{[23]}$. CLEC 3A and KLK11 are not normally expressed in lymph node tissue ${ }^{[14]}$. Furthermore, there are limited investigations on the presence of this biomarker in metastatic lymph nodes in breast cancer. The aim of this study was to find new biomarkers to improve the diagnostic accuracy in the detection of metastatic axillary lymph nodes. We used CK19 expression as a standard diagnostic tool.

\section{MATERIALS AND METHODS}

\section{Patients and source of SLN}

SLNs $(n=78)$ were obtained from axillary lymph node dissection. The specimens of 35 breast cancer patients in clinical stages I and II were acquired from the Pathology Department of Pastorno Hospital, Mashhad, Iran. All patients had operations by the same surgical team and had received no chemotherapy from February to December 2017. Based on the permanent section H\&E analysis of SLNs, the specimens were divided into two groups of reactive and metastatic lymph nodes.

\section{RNA extraction}

Five to six histological sections, $5 \mu \mathrm{m}$ in thickness, were cut from each FFPE block. Afterwards, deparaffinization was carried out using xylene, according to the Qiagen (Valencia, CA, USA) protocol. Paraffin was first dissolved by adding $1 \mathrm{ml}$ of xylene and then centrifuged at full speed for 2 minutes. The supernatant was carefully removed, and then $1 \mathrm{ml}$ of ethanol (96-100\%) was added to the pellet and mixed by vortexing and centrifuged at full speed for 2 minutes. The supernatant was removed carefully by pipetting then the pellet was dried at room temperature. Next, $240 \mu \mathrm{l}$ of buffer PKD and $10 \mu \mathrm{l}$ of proteinase K were added, respectively, mixed by vortexing, and incubated at $56{ }^{\circ} \mathrm{C}$ for $15 \mathrm{~min}$, and finally at $80^{\circ} \mathrm{C}$ for 15 min. RNA was purified by RNeasy FFPE Kit (Qiagen, Valencia, CA), and the RNA quality was confirmed by gel electrophoresis.

\section{cDNA synthesis}

In reverse transcription reactions, cDNA was synthesized using the PrimeScript ${ }^{\mathrm{TM}}$ RT Reagent Kit (TaKaRa, Japan) in accordance with the manufacturer's protocol $\left(37^{\circ} \mathrm{C}\right.$ for $15 \mathrm{~min}$ and $85^{\circ} \mathrm{C}$ for $5 \mathrm{~s}$ ). The cDNA quality was confirmed by the amplification of glyceraldehyde-3-phosphate dehydrogenase as a control.

\section{Construction of standard curves for the CK19, $C L E C 3 A$, and $K L K 11$ copy number determination}

Specific controls were constructed for CK19, CLEC 3A, and KLK11 by TA cloning of PCR products. Plasmid pBlusScript SK II (+) was used to clone the desired fragment. The recombinant vector was transformed into competent $E$. coli DH5- $\alpha$, and the transformed culture was spread on agar Luria-Bertani plates containing ampicillin $(100 \mu \mathrm{g} / \mathrm{ml})$, IPTG $(0.1 \mathrm{mM})$, and X-gal $(20 \mu \mathrm{g} / \mathrm{ml})$ and incubated at $37{ }^{\circ} \mathrm{C}$ for one night. Transformed (white) colonies were picked and processed for plasmid isolation. 

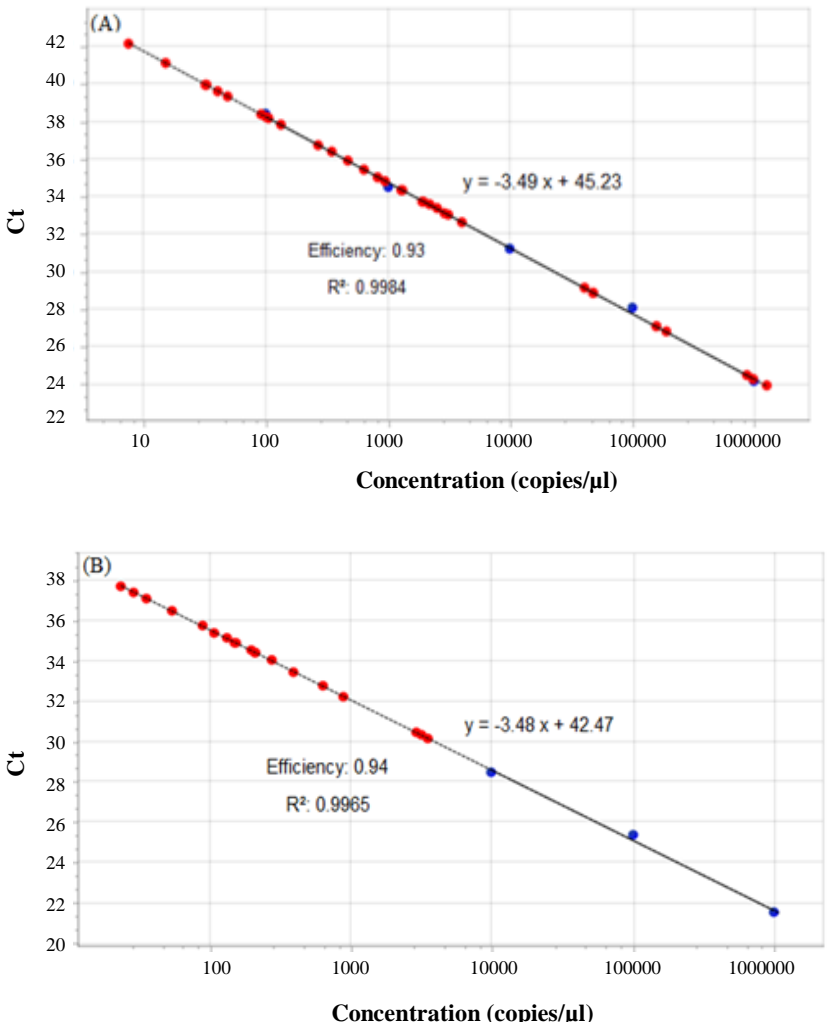

Fig. 1. Standard curves for (A) CK19 and (B) CLEC3A. The $\mathrm{Ct}$ is shown on the $\mathrm{Y}$ axis, and standard serial dilutions from $10^{6}$ to $10^{2}$ (copies $\left./ \mu \mathrm{l}\right)$ is indicated on the $\mathrm{X}$ axis. The correlation coefficient $\left(\mathrm{R}^{2}\right)$ of $C K 19$ and CLEC3A were 0.93 and 0.94 , respectively. Blue and red circles show standards and samples, respectively.

Plasmid purification was carried out using mini-prep protocol. To prepare standards with known concentrations for a standard curve, the molar concentration of the extracted plasmid was measured with NanoDrop, and then the dilution was made. Finally, standards with a concentration range of $10^{6}$ to $10^{2}$ were used to draw the standard curve (Fig. 1). For all the standards, copy numbers were calculated as below $^{[24]}$ :

$$
\text { DNA (copy) } \left.=\frac{6.02 \times 10^{23}(\text { copies mol }}{-1}\right) \times \text { DNA amount }(\mathrm{g})_{\text {DNA lenght }(\mathrm{bp}) \times 660\left(\mathrm{~g} \mathrm{~mol}^{-1} \mathrm{bp}^{-1}\right)}
$$

Absolute quantitation demonstrates the precise copy concentration of the target gene, but relative quantification determines fold changes in the expression between two samples. Absolute quantitation uses well-known diluted serial standards, and then the standard curve is designed. The standard curve provides a linear relationship between $\mathrm{Ct}$ and the initial values of the entire RNA or cDNA, which allows determining the unknown concentration based on its $\mathrm{Ct}$ values.

\section{Real-time PCR assay}

The TaqMan ${ }^{\circledR}$ real-time PCR method was performed by using StepOne ${ }^{\mathrm{TM}}$ Real-Time PCR. Specific oligonucleotide primers and probes were designed and synthesized by Macrogen, Korea (Table 1). Thermal cycling conditions were designed as follows: initial denaturation at $95{ }^{\circ} \mathrm{C}$ for $15 \mathrm{~min}$, followed by $40-45$ cycles at $95^{\circ}{ }^{\circ} \mathrm{C}$ for $30 \mathrm{~s}, 60{ }^{\circ} \mathrm{C}$ for $30 \mathrm{~s}$, and $72{ }^{\circ} \mathrm{C}$ for 30 s. All reactions for each gene in reactive and positive samples were run in triplicate.

\section{Statistical analysis}

Statistical analysis was performed using SPSS22 software. Results were reported as mean \pm standard deviation. The Kolmogorov-Smirnov test was used for normal or abnormal distribution of the data, as well as in percentage descriptions. The relationship between the expression of biomarkers and cancer histology was assessed by linear regression analysis (Mann-Whitney U test). Kruskal Wallis was employed to compare the groups. The ROC analysis and the AUC were calculated to evaluate the diagnostic values of the markers. Statistically significant correlation was indicated by $p<0.05$.

\section{Ethical statement}

The above-mentioned sampling protocols were approved by the Ethics Committee of Mashhad University of Medical Sciences (ethical code: IR. mums.fm.rec. 1396.265). Written informed consents were provided by all the participants.

Table 1. Sequences of primers and probes used in real-time RT-PCR

\begin{tabular}{ll}
\hline Primer/probe & Oligonucleotide sequence (5'-3') \\
\hline CK19 F & 5'-GGC CTA CCT GAA GAA GAA CCA-3' (21 mer) \\
CK19 R & 5'-AAT CCA CCT CCA CAC TGA CC-3' (20 mer) \\
CK19 probe & 5'-FAM-AGT ACG CTG AGG GGC CAA G-BHQ1-3' (19 mer) \\
KLK11 R & 5'-GAT GGT GAT GTT GGC GCA T-3' (19 mer) \\
KLK11 F & 5'-CAG CTG CCT CAT TTC CGG-3' (18 mer) \\
KLK11 probe & 5'-FAM-CAG TTA CGC CTG CCT CAC AC-BHQ1-3' (20 mer) \\
CLEC3A F & 5'-GGA CTT GTA ATT TGC ATC CTG GT-3' (23 mer) \\
CLEC3A R & 5'-CCA GAG CTT TTC AAT TTG AGT CT-3' (23 mer) \\
CLEC3A probe & 5'-FAM-CAG GAA GCA CAG CAA ACG TC-BHQ1-3' (20 mer $)$ \\
\hline
\end{tabular}

$\mathrm{F}$, forward primer $\mathrm{R}$, reverse primer 
Table 2. Clinicopathological characteristics of patients

\begin{tabular}{|c|c|}
\hline Characteristics & Patients $(n=35)$ \\
\hline \multicolumn{2}{|l|}{ Age (y) } \\
\hline Total & 35 \\
\hline$\leq 50$ & 15 \\
\hline$>50$ & 20 \\
\hline Mean & $50 / 2$ \\
\hline \multicolumn{2}{|l|}{ Histological type } \\
\hline Ductal & 34 \\
\hline Lobular & 1 \\
\hline \multicolumn{2}{|l|}{ Grading } \\
\hline GI & 5 \\
\hline GII & 22 \\
\hline GIII & 8 \\
\hline \multicolumn{2}{|l|}{ Tumor size } \\
\hline T1 (0-1.9) & 15 \\
\hline $\mathrm{T} 2(2-3.9)$ & 20 \\
\hline \multicolumn{2}{|l|}{ Tumor stage } \\
\hline IA & 15 \\
\hline IIA & 20 \\
\hline \multicolumn{2}{|c|}{ Clinical lymph node status } \\
\hline $\mathrm{N} 1$ & 30 \\
\hline $\mathrm{N} 2$ & 5 \\
\hline \multicolumn{2}{|l|}{ Pathologic stage } \\
\hline IIA & 14 \\
\hline IIB & 16 \\
\hline IIIA & 5 \\
\hline \multicolumn{2}{|l|}{ Estrogen receptor } \\
\hline Negative & 8 \\
\hline Positive & 27 \\
\hline \multicolumn{2}{|c|}{ Progesterone receptor } \\
\hline Negative & 9 \\
\hline Positive & 25 \\
\hline \multicolumn{2}{|l|}{ Her2/neu } \\
\hline Negative & 26 \\
\hline Positive & 9 \\
\hline \multicolumn{2}{|l|}{ Ki67 } \\
\hline Negative & 3 \\
\hline Positive & 32 \\
\hline
\end{tabular}

\section{RESULTS}

\section{Patient histopathological characteristics}

A total of 79 lymph nodes from FFPE samples of 35 breast cancer patients were evaluated. It should be noted that patients did not receive any neoadjuvant therapy. According to the pathology results, we stratified patients on the basis of their pathologic status of SLNs into two groups. The first group (I) consisted of 15 patients with 27 pathologically negative lymph nodes, and the second group (II) included 20 patients with 52 metastatic lymph nodes. The age of the patients ranged from 27 to 68 years (mean 50.2), and the clinicopathological findings of these patients are depicted in (Table 2).

\section{Quantitation of CK19, KLK11, and CLEC3A mRNAs expression in lymph nodes}

We used absolute quantitative real-time RT-PCR to determine the expression of CK19, KLK11, and CLEC 3A mRNAs, pathologically negative and positive lymph nodes. The actual copy numbers of target genes were also determined by relating the $\mathrm{Ct}$ value to a standard curve. The expression levels of the three mRNAs differed histopathologically between positive and negative lymph nodes (Table 3 ).

\section{Expression analysis of $C K 19, K L K 11$ and $C L E C 3 A$ mRNAs in samples \\ CK19 gene expression}

Based on the real-time PCR data, the minimum and maximum values of CK19 expression among all samples were 15.1 and 1028629.6 copies $/ \mu \mathrm{L}$, respectively, and a statistically significant $(p=0.005)$ up-regulation of $C K 19$ was found in group II compared to group I (Fig. 2A). Expression of the CK19 mRNA, according to cut-off numbers, are illustrated in Figure 3. As shown in group I (reactive), the results were as $46.2 \%$ negative, $46.2 \%$ micrometastasis, and 7.7\% macrometastasis (false-negative cases). Group II (involved) demonstrated 50\% micrometastasis and

Table 3. Mean Ct values and mean copy numbers of the CK19, KLK11, and CLEC3A using real-time RT-PCR

\begin{tabular}{llcc}
\hline $\begin{array}{l}\text { mRNA } \\
\text { markers }\end{array}$ & Nodal status & $\begin{array}{c}\text { Mean Ct } \\
\text { value }\end{array}$ & $\begin{array}{c}\text { Mean copy } \\
\text { number }\end{array}$ \\
\hline \multirow{2}{*}{ CK19 } & Pathologically reactive node (group I) & 37.57 & 374.20 \\
& Pathologically involved node (group II) & 32.97 & 48351.90 \\
& & & \\
& & 37.02 & 62.96 \\
PLK11 & Pathologically reactive node (group I) & 35.06 & 194.70 \\
& & & \\
\multirow{2}{*}{ CLEC3A } & Pathologically involved node (group II) & 35.60 & 44.50 \\
& Pathologically involved node (group II) & 34.76 & 78.10 \\
\hline
\end{tabular}



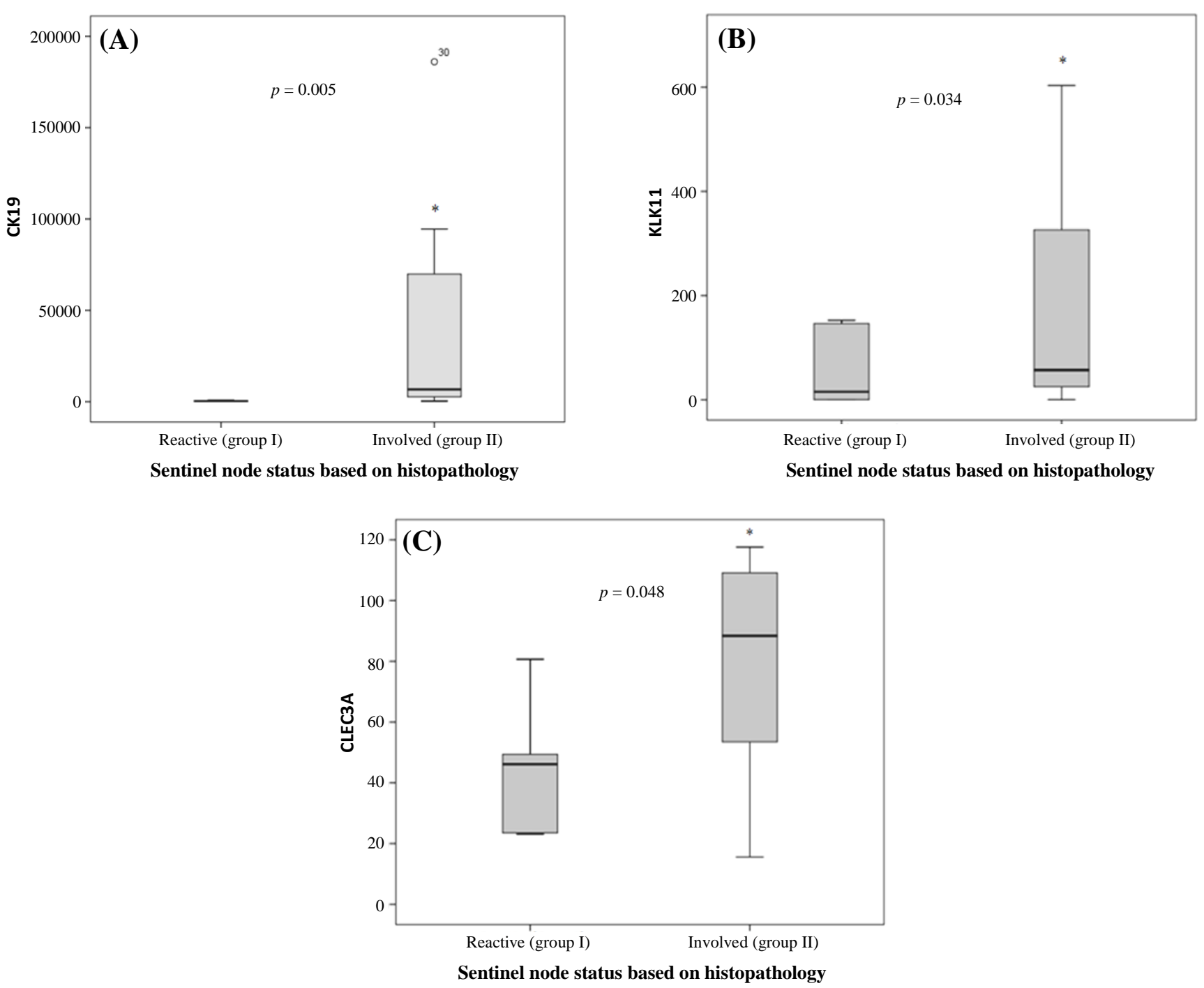

Fig. 2. Comparing mRNA expression in group I (reactive) and group II (involved) of lymph nodes. (A) CK19, (B) KLK11, and (C) $C L E C 3 A$ expressions. ${ }^{*}$ The expression of all markers in group II significantly increased compared with group I. Lines in the middle show the mean expression value.

$35 \%$ macrometastasis, which is expected and consistent with pathologic reports. Based on the MannWhitney $\mathrm{U}$ test, the mean $C K 19$ between the two groups was statistically significant $(p=0.005)$.

\section{KLK11 gene expression}

The average value of $K L K 11$ mRNA expression for groups I and II were 62 and 194 copies/ $\mu 1$, respectively (Fig. 2B), and the lowest limit of detection was 0.1386 . Based on the Mann-Whitney $\mathrm{U}$ test, the mean KLK11 expression difference between the two groups was not statistically significant $(p=0.034)$.

\section{CLEC3A gene expression}

The expression levels of CLEC $3 A$ mRNA in groups I and II were 44 and 79 copies/ $\mu \mathrm{L}$, respectively (Fig. 2C). The minimum limit of detection was 15.581 copies/ $\mu \mathrm{L}$. Based on Mann-Whitney U, a statistically significant $(p=0.048)$ up-regulation of CLEC3A mRNA was observed between the two groups. Also, there was an independent correlation among the three markers $(p>0.05)$.

\section{ROC curve analysis}

The diagnostic value of the CK19, KLK11, and CLEC3A mRNAs was quantified by the ROC curve (Fig. 4). This discrimination was measured by the AUC. The AUC for CK19 $(p=0.006)$ indicated that the results of the ROC analysis were reliable. The AUC $=0.788(95 \%$ CI: 0.688-0.945) was consistent with the moderate accuracy test. According to the 250 copies cut-off point for this gene, the specificity was $46 \%$, and the sensitivity was $85 \%$. 


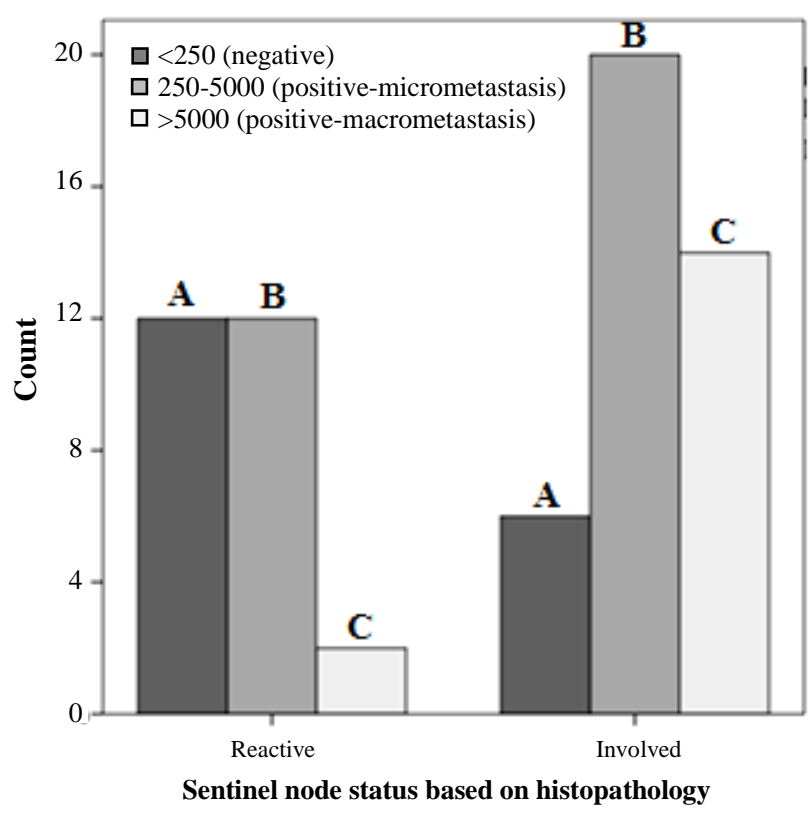

Fig. 3. Correlation between histopathology results and $C K 19$ cut-off number in the entire series of 79 SLNs. Group I (reactive): by $C K 19$ copy number (A) $46.2 \%$ negative, (B) 46.2\% micrometastasis, and (C) 7.7\% macrometastasis. Group II (involved): by $C K 19$ copy number (A) $15 \%$ negative, (B) $50 \%$ micrometastasis, and $(\mathrm{C}) 35 \%$ macrometastasis, $(p=0.005)$.

The AUC for KLK11 was not meaningful $(p=$ $0.310)$. In $C L E C 3 A$, the AUC was significant ( $p=$ 0.046); therefore, the results showed to be reliable. The amount of $\mathrm{AUC}=0.743$ (95\% CI: 0.535-0.951) corresponded to the moderate test accuracy. According to the ROC analysis, we identified a cut-off of 50 copies/ $\mu \mathrm{L} C L E C 3 A$ mRNA with $78 \%$ sensitivity and $60 \%$ specificity. Depending on the determined cut-off for the CLEC3A, in group I, patients were $60 \%$ CLEC3A-negative and 40\% CLEC3A-positive, and in group II, $21.2 \%$ CLEC $3 A$-negative and $78.5 \%$ CLEC3A-positive. The percentage of positive and negative SLNs on the basis of the cut-off number of CLEC3A and CK19 is presented in Table 4.

The evaluation of the relationship between KLK11 expression and patients with different nuclear grades by using the Kruskal-Wallis statistical test indicated that the average KLK11 with tumor grade was statistically significant $(p=0.017)$, and in grade $\mathrm{I}$, it was higher than grade II and III (Fig. 5B). It seemed that the lower levels of $C L E C 3 A$ were associated with the greater involvement of the lymph node (N2 versus N1).

The mean CK19 had a statistically significant association with tumor invasion depth ( $\mathrm{T}$; MannWhitney $\mathrm{U}$ test, $p<0.0001$; Fig. 5A), but this relationship was not significant for the other two markers $(p>0.05)$. A lower value of CK19 was associated with a lower invasion depth (T1 versus $\mathrm{T} 2$ ). The mean CK19 was statistically correlated with the stage of the tumor (Kruskal-Wallis test, $p=0.001$ ), but this relation was not significant for the other two markers $(p>0.05)$. It seemed that the amount of $C K 19$ at the lowest stage (IIA) was less than the two other stages.

\section{DISCUSSION}

A variety of reports have described more accurate diagnosis of micrometastasis in axillary lymph nodes, by using reverse transcription of some indicators such as prolactin-induced protein, CK19, mammaglobin, carcinoembryonic acid, and MUCl. Among these makers, CK19 and mammaglobin have illustrated high sensitivity and specificity for the detection of lymph node metastasis of breast cancer $^{[25]}$. Due to high reliability, these two markers have currently used clinically.

CK19 is known as an epithelial cell marker and is widely expressed in more than $90 \%$ of breast cancers. In previous studies of $C K 19$ detection, one-step nucleic acid amplification was identified as a valuable intra-
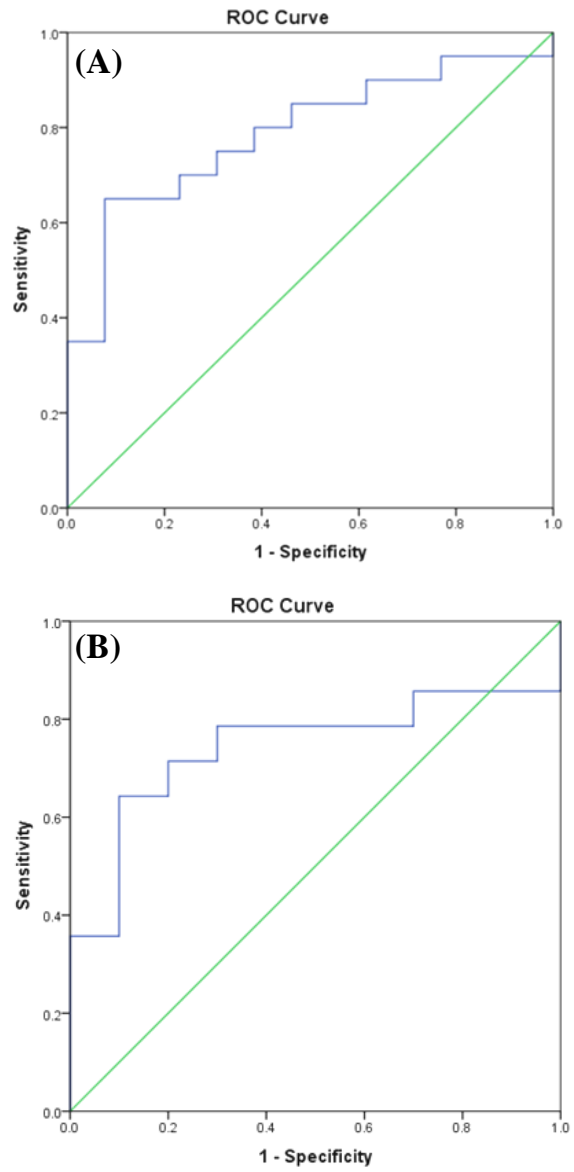

Fig. 4. ROC curve for $(\mathrm{A}) C K 19(\mathrm{AUC}=0.788)$ and $(\mathrm{B})$ CLEC $3 A(\mathrm{AUC}=0.743)$. 
Table 4. Sensitivity and specificity of real-time RT-PCR of CK19 and CLEC3A

\begin{tabular}{|c|c|c|c|c|c|}
\hline \multirow[b]{2}{*}{ Nodal status } & \multicolumn{3}{|c|}{$\begin{array}{c}\text { CK19 } \\
(\text { cut-off value }=\mathbf{2 5 0})\end{array}$} & \multicolumn{2}{|c|}{$\begin{array}{c}C L E C 3 A \\
\text { (cut-off value }=50)\end{array}$} \\
\hline & $\begin{array}{l}\text { Macrometastasis } \\
>\mathbf{5 0 0 0}(\%)\end{array}$ & $\begin{array}{c}\text { Micrometastasis } \\
\mathbf{2 5 0 - 5 0 0 0}(\%)\end{array}$ & $\begin{array}{l}\text { Negative } \\
<250(\%)\end{array}$ & $\begin{array}{c}\text { Positive } \\
(\%)\end{array}$ & $\begin{array}{c}\text { Negative } \\
(\%)\end{array}$ \\
\hline Pathologically reactive node (group I) & 40 & 60 & 7.7 & 46.2 & 46.2 \\
\hline Pathologically involved node (group II) & 78.5 & 21.2 & 35.0 & 50.0 & 15.0 \\
\hline Sensitivity (\%) & \multicolumn{2}{|c|}{0.78} & & \multicolumn{2}{|c|}{0.85} \\
\hline Specificity (\%) & \multicolumn{2}{|c|}{0.60} & & \multicolumn{2}{|c|}{0.46} \\
\hline
\end{tabular}

operative approach for the diagnosis of lymph node metastases in patients with breast cancer and defined as having the highest sensitivity (about 90\%) ${ }^{[26,27]}$. Based on $C K 19$ cut-off numbers, we observed $92.4 \%$ negative nodes (less than 250 copies) for group I and $85 \%$ positive lymph nodes (more than 250 copies) for group II, which can be expected and is consistent with the pathologic results. Fujisue et al. ${ }^{[28]}$ have reported that the negative cases of $C K 19$ are clearly associated with a negative level of ER-PR and higher levels of Ki67 expression, as well as higher nuclear grade and higher expression of P53. In cases where breast cancer is triple-negative, the expression of CK19 is lower. On the contrary, we observed no significant relationship between chosen biomarkers and ER-PR and Ki67 and Her2/neu expression. Although extensive research has been carried out on identified markers for detecting lymph node involvement in breast cancer, there is still a need to identify newer markers with higher sensitivity and specificity.

Pursuant to the next-generation RNA sequencing study by Feng Liang et $a l^{[14]}$ in non-SLN-positive group, $C Y P 2 A 13, K L K 11$, and CLEC $3 A$ demonstrated higher overexpression. Biomarkers identified in this

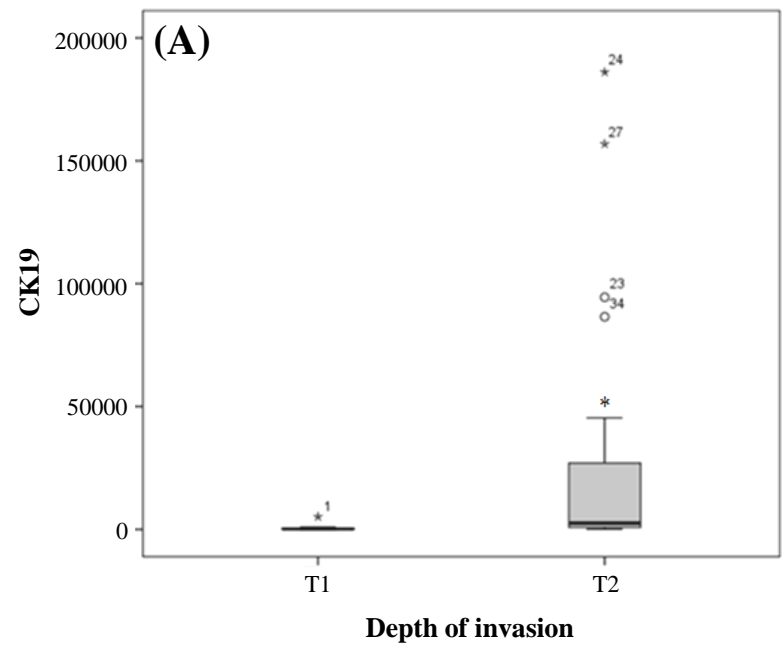

study can provide a new understanding of the mechanism of breast and lymph node involvement, as well as the selection of patients for surgery. Hence, we selected KLK11 and CLEC $3 A$ as new biomarkers to detect metastatic SLNs. Evidence has suggested that Kallikreins play a role in cancer, and some of them are potentially new markers of cancer and other biological diseases ${ }^{[29]}$. It has also been shown that the expression of KLK11 in breast cancer contributes significantly to the progression of cancer by increasing the bioavailability of IGF through degradation of IGFBP$3^{[30]}$, and extremely significant expression of $K L K 11$ was observed in patients with breast cancer grades I and II compared to III. In agreement with the results reported by Sano et al. ${ }^{[30]}$, our results displayed a significant reverse correlation between overexpression of $K L K 11$ and tumor grade. CLEC $3 A$ is specifically expressed in the cartilage, and a significant expression in the breast and colon cancer tissue has been identified $^{[16,31]}$. The expression of CLEC $3 A$ in breast IDC was higher than the normal tissue of the breast and axillary lymph nodes (pathologic N1 versus N0). Increasing the expression of $C L E C 3 A$ may correlate with the metastatic potential of the IDC breast, which

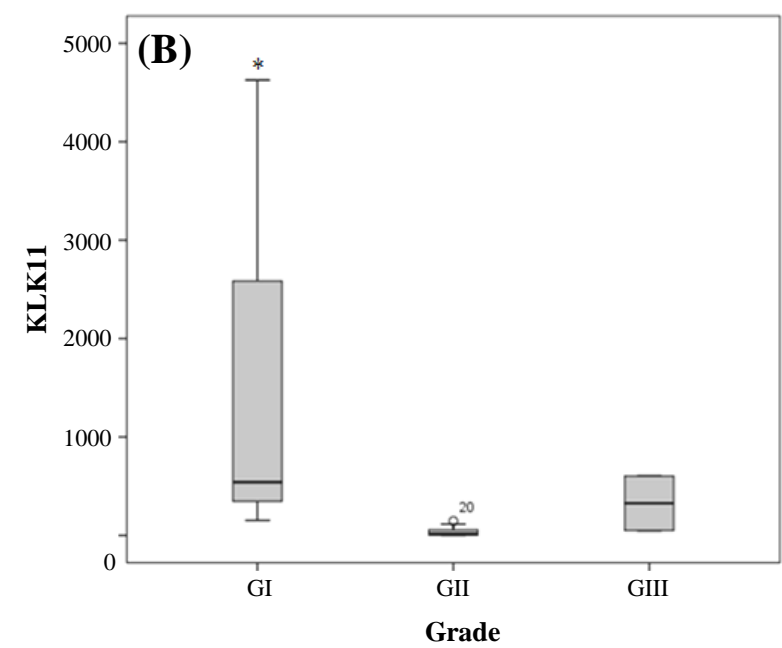

Fig. 5. (A) Relationship between $C K 19$ and tumor invasion depth (T). ${ }^{*} C K 19$ expression in invasion depth (T2) is higher than (T1) $(p<0.0001)$; (B) relationship between KLK11 and tumor grades. ${ }^{*} K L K 11$ expression in grade I is higher than grade II and III $(p=$ $0.017)$. 
indicates a poor prognosis in the IDC of the breast ${ }^{[32]}$.

Based on our results, the mean expression of this gene was significantly different between the two groups. In order to obtain the highest sensitivity and specificity with an optimal cut-off value, the ROC curve analysis was utilized. ROC analysis indicated the absolute sum of sensitivity and specificity regarding the single copy number cut-offs. The best cut-off for our purpose was specified with a higher AUC. The cutoff value was estimated at $50 / \mu \mathrm{L}$ copies of $C L E C 3 A$ mRNA, on the basis of the ROC analysis with an AUC equal to 0.743 , copy number of $50 / \mu \mathrm{L}$, indicating the sensitivity of $78 \%$ and a specificity of $60 \%$. The results from the analysis of CLEC $3 A$ expression levels revealed a higher CLEC3A level in metastatic SLN compared to normal tissue (N0 versus N1) and also a higher expression in N1 versus $\mathrm{N} 2(p=0.04)$. Positive and negative predictive values of this test were $100 \%$ and $35 \%$, respectively, and the diagnostic value of the CLEC $3 A$ gene can be as much as $C K 19$.

In summary, although very limited study has been conducted on the expression levels of KLK11 and CLEC 3A mRNAs in the SLN tissue in breast cancer, we observed the overexpression of these genes in the positive SLN tissue similar to the CK19 biomarker. Based on our results, the expression of all the three biomarkers increased in group II without any correlation among them. We also found a significant correlation between mean KLK11 and CLEC 3A values with nuclear grade $(\mathrm{G})$ and lymph node status $(\mathrm{N})$, respectively. Additionally, higher CK19 values were found to be associated with a more invasive tumor, involvement of the SLN, and a higher stage of cancer. We set a cut-off point for CLEC $3 A$, but more precise cut-offs can be determined by increasing the number of patients and following up with them. The expression profile of CLEC $3 A$, as a useful benchmark described in this study, supports the clinical utility of this biomarker in the diagnosis of metastatic SLNs in breast carcinoma, but more encouraging results merit further investigation.

\section{ACKNOWLEDGMENTS}

The present work was supported by the grant no. 951669 from the Mashhad University of Medical Sciences, Mashhad, Iran. The authors would like to express their very great appreciation to Dr. Majid Mojarrad, Head of the Department of Medical Genetics, Mashhad University of Medical Sciences, Mashhad, Iran and Dr. Khashayar Atqiaee, General surgeon, Shahid Beheshti University of Medical Sciences, Tehran, Iran and Dr. Mehdi Montazer for their valuable and constructive suggestions during the planning and development of this research work. Their willingness to give their time so generously has been very much appreciated.

\section{CONFLICT OF INTEREST. None declared}

\section{REFERENCES}

1. Parkin DM, Bray F, Ferlay J, Pisani P. Global cancer statistics, 2002. CA: a cancer journal for clinicians 2005; 55(2): 74-108.

2. Kuerer HM, Sahin AA, Hunt KK, Newman LA, Breslin TM, Ames FC, Ross MI, Buzdar AU, Hortobagyi GN,Singletary SE. Incidence and impact of documented eradication of breast cancer axillary lymph node metastases before surgery in patients treated with neoadjuvant chemotherapy. Annals of surgery 1999; 230(1): 72-78.

3. Lyman GH, Giuliano AE, Somerfield MR, Benson AB 3rd, Bodurka DC, Burstein HJ, Cochran AJ, Cody HS 3rd, Edge SB, Galper S, Hayman JA, Kim TY, Perkins CL, Podoloff DA, Sivasubramaniam VH, Turner RR, Wahl R, Weaver DL, Wolff AC, Winer EP; American Society of Clinical Oncology. American Society of Clinical Oncology guideline recommendations for sentinel lymph node biopsy in early-stage breast cancer. Journal of clinical oncology 2005; 23(30): 7703-7720.

4. Weiser MR, Montgomery LL, Susnik B, Tan LK, Borgen PI, Cody HS. Is routine intraoperative frozensection examination of sentinel lymph nodes in breast cancer worthwhile? Annals of surgical oncology 2000; 7(9): 651-655.

5. St John ER, Al-Khudairi R, Ashrafian H, Athanasiou T, Takats Z, Hadjiminas DJ, Darzi A, Leff DR. Diagnostic accuracy of intraoperative techniques for margin assessment in breast cancer surgery. Annals of surgery 2017; 265(2): 300-310.

6. Tew K, Irwig L, Matthews A, Crowe P, Macaskill P. Meta-analysis of sentinel node imprint cytology in breast cancer. British journal of surgery 2005; 92(9): 1068-1080.

7. Layfield DM, Agrawal A, Roche H, Cutress R. Intraoperative assessment of sentinel lymph nodes in breast cancer. British journal of surgery 2011; 98(1): 417.

8. Noguchi S, Aihara T, Nakamori S, Motomura K, Inja H, Imaka S, Koyama $\mathrm{H}$. The detection of breast carcinoma micrometastases in axillary lymph nodes by means of reverse transcriptase-polymerase chain reaction. Cancer 1994; 74(5): 1595-1600.

9. Schoenfeld A, Luqmani Y, Smith D, O'Reilly S, Shousha S, Sinnett HD, Coombes RC. Detection of breast cancer micrometastases in axillary lymph nodes by using polymerase chain reaction. Cancer research 1994; 54(11): 2986-2990.

10. Bostick PJ, Chatterjee S, Chi DD, Huynh KT, Giuliano AE, Cote R, Hoon DS. Limitations of specific reversetranscriptase polymerase chain reaction markers in the detection of metastases in the lymph nodes and blood of 
breast cancer patients. Journal of clinical oncology 1998; 16(8): 2632-2640.

11. Chu PG, Weiss LM. Keratin expression in human tissues and neoplasms. Histopathology 2002; 40(5): 403-439.

12. Abd El-Rehim DM, Pinder SE, Paish CE, Bell J, Blamey RW, Robertson JF, Nicholson RI, Ellis IO. Expression of luminal and basal cytokeratins in human breast carcinoma. The journal of pathology 2004; 203(2): 661-671.

13. Tsujimoto M, Nakabayashi K, Yoshidome K, Kaneko T, Iwase T, Akiyama F, Kato Y, Tsuda H, Ueda S, Sato K, Tamaki Y, Noguchi S, Kataoka TR, Nakajima H, Komoike Y, Inaji H, Tsugawa K, Suzuki K, Nakamura S, Daitoh M, Otomo Y, Matsuura N. One-step nucleic acid amplification for intraoperative detection of lymph node metastasis in breast cancer patients. Clinical cancer research 2007; 13(16): 4807-4816.

14. Liang F, Qu H, Lin Q, Yang Y, Ruan X, Zhang B, Liu $\mathrm{Y}$, Yu C, Zhang $\mathrm{H}$, Fang $\mathrm{X}$, Hao $\mathrm{X}$. Molecular biomarkers screened by next-generation RNA sequencing for non-sentinel lymph node status prediction in breast cancer patients with metastatic sentinel lymph nodes. World journal of surgical oncology 2015; 13: 258.

15. Zelensky AN, Gready JE. The C-type lectin-like domain superfamily. The FEBS journal 2005; 272(24): 61796217.

16. Neame PJ, Young CN, Treep JT. Primary structure of a protein isolated from reef shark (Carcharhinus springeri) cartilage that is similar to the mammalian C-type lectin homolog, tetranectin. Protein science 1992; 1(1): 161168.

17. Tsunezumi J, Higashi S, Miyazaki K. Matrilysin (MMP-7) cleaves C-type lectin domain family 3 member A (CLEC3A) on tumor cell surface and modulates its cell adhesion activity. Journal of cellular biochemistry 2009; 106(4): 693-702.

18. Lau D, Elezagic D, Hermes G, Mörgelin M, Wohl AP, Koch M, Hartmann U, Höllriegl S, Wagener R, Paulsson M, Streichert T, Klatt AR. The cartilagespecific lectin C-type lectin domain family 3 member A (CLEC3A) enhances tissue plasminogen activatormediated plasminogen activation. Journal of biological chemistry 2018; 293(1): 203-214.

19. Borgoño CA, Michael IP, Diamandis EP. Human tissue kallikreins: physiologic roles and applications in cancer. Molecular cancer research 2004; 2(5): 257-280.

20. Nakamura T, Mitsui S, Okui A, Kominami K, Nomoto T, Ukimura O, Kawauchi A, Miki T, Yamaguchi N. Alternative splicing isoforms of hippostasin (PRSS20/KLK11) in prostate cancer cell lines. The prostate $2001 ;$ 49(1): 72-78.

21. Shigemasa K, Gu L, Tanimoto H, O'Brien TJ, Ohama K. Human kallikrein gene 11 (KLK11) mRNA overexpression is associated with poor prognosis in patients with epithelial ovarian cancer. Clinical cancer research 2004; 10(8): 2766-2770.

22. Bhattacharjee A, Richards WG, Staunton J, Li C, Monti S, Vasa P, Ladd C, Beheshti J, Bueno R, Gillette M, Loda M, Weber G, Mark EJ, Lander ES, Wong W, Johnson BE, Golub TR, Sugarbaker DJ, Meyerson M. Classification of human lung carcinomas by mRNA expression profiling reveals distinct adenocarcinoma subclasses. Proceedings of the national academy of sciences USA 2001; 98(24): 13790-13795.

23. Diamandis EP, Okui A, Mitsui S, Luo LY, Soosaipillai A, Grass L, Nakamura T, Howarth DJ, Yamaguchi N. Human kallikrein 11: a new biomarker of prostate and ovarian carcinoma. Cancer research 2002; 62(1): 295300.

24. Godornes C, Leader BT, Molini BJ, Centurion-Lara A, Lukehart SA. Quantitation of rabbit cytokine mRNA by real-time RT-PCR. Cytokine 2007; 38(1): 1-7.

25. Mitas M, Mikhitarian K, Walters C, Baron PL, Elliott BM, Brothers TE, Robison JG, Metcalf JS, Palesch YY, Zhang Z, Gillanders WE, Cole DJ. Quantitative real-time RT-PCR detection of breast cancer micrometastasis using a multigene marker panel. International journal of cancer 2001; 93(2): 162-171.

26. Catherine Alix-Panabières, Jean-Pierre Vendrell, Monique Slijper, Olivier Pellé, Eric Barbotte, Grégoire Mercier, William Jacot, Michel Fabbro, Klaus Pante. Full-length cytokeratin-19 is released by human tumor cells: a potential role in metastatic progression of breast cancer. Breast cancer research 2009; 11(3): R39.

27. Alvarenga CA, Paravidino PI, Alvarenga M, Dufloth R, Gomes M, Zeferino LC, Schmitt F. Expression of CK19 in invasive breast carcinomas of special histological types: implications for the use of one-step nucleic acid amplification. Journal of clinical pathology 2011; 64(6): 493-497.

28. Fujisue M, Nishimura R, Okumura Y, Tashima R, Nishiyama Y, Osako T, Toyozumi Y, Arima N. Clinical significance of CK19 negative breast cancer. Cancers (Basel) 2013; 5(1): 1-11.

29. Yousef GM, Yacoub GM, Polymeris ME, Popalis C, Soosaipillai A, Diamandis E. Kallikrein gene downregulation in breast cancer. British journal of cancer 2004; 90(1): 167-172.

30. Sano A, Sangai T, Maeda H, Nakamura M, Hasebe T, Ochiai A. Kallikrein 11 expressed in human breast cancer cells releases insulin-like growth factor through degradation of IGFBP-3. International journal of oncology 2007; 30(6): 1493-1498.

31. Neame PJ, Tapp H, Grimm DR. The cartilage-derived, C-type lectin (CLECSF1): structure of the gene and chromosomal location. Biochimica et biophysica acta 1999; 1446(3): 193-202.

32. Ni J, Peng Y, Yang FL, Xi X, Huang XW, He C. Overexpression of CLEC3A promotes tumor progression and poor prognosis in breast invasive ductal cancer. Onco targets and therapy 2018; 11: 3303-3312. 